\title{
Microstructural behavior of SAF 2205 Duplex Stainless Steel Welded by Friction Hydro Pillar Processing
}

\author{
Cleber Rodrigo de Lima Lessa ${ }^{a *}$, Douglas Martinazzi ${ }^{b}$, Arlan Pacheco Figueiredo ${ }^{a}$, Rodrigo Batista
}

Machado $^{b}$, Claudia Fanezi $i^{b}$, Telmo Strohaecker ${ }^{b}$

\author{
${ }^{a}$ Instituto Federal do Rio Grande do Sul - IFRS, Caxias do Sul, 95043-700, Rio Grande do Sul-RS, \\ Brazil \\ ${ }^{b}$ Departamento de Metalurgia - DEMET, Universidade Federal do Rio Grande do Sul-UFRGS, 90035- \\ 190, Porto Alegre, RS, Brazil
}

Received: January, 14, 2016; Revised: May, 07, 2016; Accepted: June, 24, 2016

\begin{abstract}
The Friction Hydro-Pillar Process (FHPP) is an innovative process that has been recently studied regarding its possible in situ repair applications. There is still no literature about usage of the FHPP on duplex stainless steel (DSS) base materials to smaller forces than $25 \mathrm{kN}$. The investigation on DSS processing is crucial due his wide variety of critical uses in pipes and storage structures applied in chemical industry plants, where usual welding processes may lead to safety concerns. The aim of this study is to qualify the processing of SAF 2205 (UNS 31803) duplex stainless steel welded joints using FHPP as feasible repair procedure. For this, the studied samples were welded applying a range of axial forces. The welded joints were characterized by, $\alpha / \gamma$ phase ratio, intermetallic quantification, austenite spacing measurement, microhardness profile and microstructural qualitative studies. The results showed the efficiency in repair of the FHPP process on the production of DSS joints according with the material recommendations from the standard DNV-RP-F112.
\end{abstract}

\section{Keywords: Friction Hydro Pillar Processing; Duplex stainless steel; Repair; Microstructure}

\section{Introduction}

The duplex stainless steels (DSSs), characterized by ferrite-austenite dual phase microstructures, are widely used in petrochemical, oil, chemical, nuclear and marine industries because of their combination of high mechanical strength and good corrosion resistance in aggressive environments ${ }^{1}$. The SAF 2205 may be referred as the most extensively DSS used nowadays, constituting approximately $80 \%$ of its total amount consumed ${ }^{2}$. However, due to high chromium $(22 \% \mathrm{Cr})$ and molybdenum $(\sim 3 \% \mathrm{Mo})$ contents and their high diffusion rate in ferrite, DSSs present a tendency to form unwanted secondary phases during exposure to temperatures between 400 and $1000^{\circ} \mathrm{C}^{3,4}$. Besides, thermal processes that involve long exposition periods of DSS to high temperature, may aggravate the appearance of Mo-enriched $\chi$ phase $^{3,5}$. The high degree of $\chi$ phase precipitation is also associated to negative effects on corrosion and mechanical properties ${ }^{6,7}$.

In industrial plants it is common to have the requirement of maintenance intervention due to safety regulation. Normally, conventional arc welding processes are employed in cases where structure repairs are needed. The concept of filling weld repair of localized damage process which allow fast, efficient and cost-effective led to the design of Friction Hydro Pillar Processing (FHPP $)^{6,8-10}$ macrostructure and mechanical properties in AISI 4140 steel. It also presents 3D residual stress data for a typical friction taper stud weld. Applied downwards force, rotational speed and plunge depth (equivalent to consumable length. The FHPP was initially developed by specialists at TWI (The Welding Institute)

* e-mail: cleber.lessa@caxias.ifrs.edu.br aiming to create a safer and more efficient technique weld joints production and localized damage repairing in metallic structures ${ }^{11}$. The process involves firstly the machining a hole in order to remove the region containing a previous detrimental discontinuity followed by co-axial rotation a consumable plug under controlled load generating frictional heat which continuously produces a plasticized layer responsible for the complete hole filling ${ }^{8,12}$ (Figure 1 and Figure 2). This process occur in the materials in solid state, promoting then less microstructural alteration and lower residual stress levels than conventional arc welding, which depends upon the materials fusion and solidification. Hence, the result of having minor microestructural modifications in base materials is the possibility of using this welding process in situ, i.e., without the necessity of any requirement of plant shutdown in order to repair a single or group of components. Consequently, FHPP welds may offer considerable time, energy and cost savings over fusion welding in repairs applications ${ }^{10}$ macrostructure and mechanical properties in AISI 4140 steel. It also presents 3D residual stress data for a typical friction taper stud weld. Applied downwards force, rotational speed and plunge depth (equivalent to consumable length. Further research on the FHPP technique extended its potential applications to crack repair ${ }^{11,13}$, hole filling ${ }^{9,14}$, cladding and material processing ${ }^{8}$. Due to this processing adaptable quality, further works showed its applicability in different materials such as low carbon steels with different axial forces, 50, 200, 250, 300, 350 and $400 \mathrm{kN}^{8,9,15,16}$. Pinheiro joined different magnesium $(\mathrm{Mg})$ materials using $\mathrm{FHPP}^{17}$. This process was used on the repair of undersea structures, including oil pipelines ${ }^{18-20}$. It was already studied FHPP process with DSS material, but the force was 200 


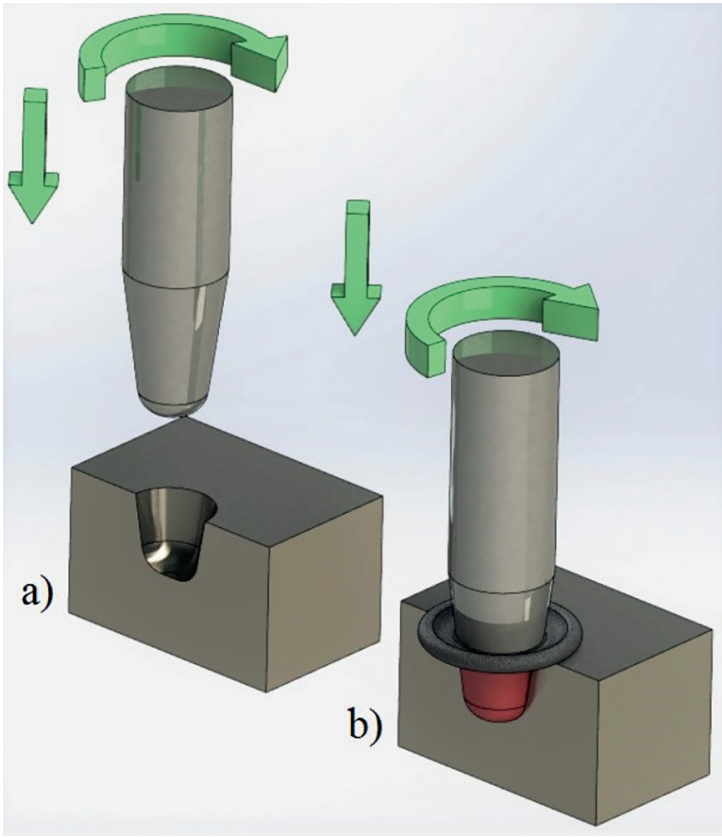

Figure 1: Schematic illustration showing FHPP process. a) Rotating consumable plug co-axially, b) processing and pressed against structure.
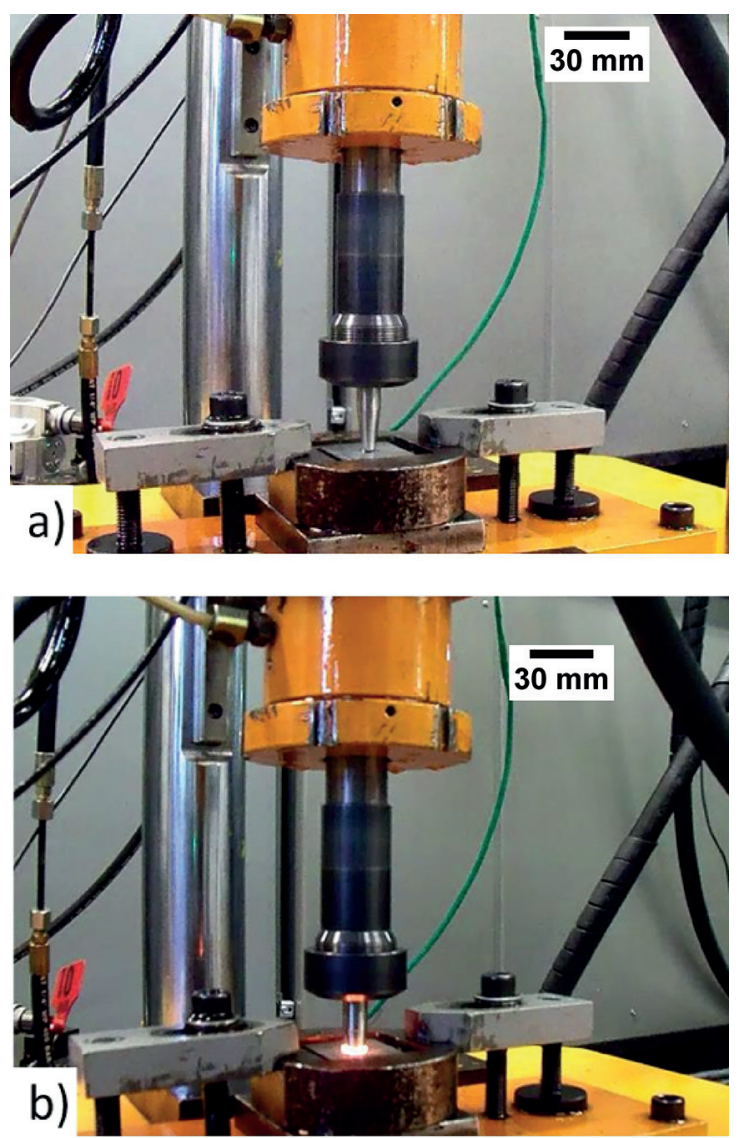

Figure 2: FHPP Processing. a) Rotating consumable plug co-axially, b) processing and pressed against structure.
$\mathrm{kN}$ which resulted joint with good toughness ${ }^{21}$. The FHPP can be automated ${ }^{6}$ and distance operated ensuring greater reproducibility ${ }^{19}$. This process may presents few disadvantages as lack of bond, incompletely filled groove and a complex mechanical and metallurgical characterization ${ }^{9}$.

The aim of this study is to qualify the processing of SAF 2205 (UNS 31803) duplex stainless steel welded joints using FHPP as feasible repair procedure utilizing lower force than those used in last works. The motivation to this study is to generate knowledge about the FHPP process applied in SAF 2205 to be one more weld process capable to repairing localized damage in structures that use this type of material. The way to approach will be through metallurgical characterization and mechanical test.

\section{Experimental procedure}

As the base metal (BM) and the plug, the material selected was SAF 2205 (UNS 31803) duplex stainless steel. The chemical composition of those materials is shown in Table 1. Before welding, DSS 2205 base metal were machined into four specimens in the dimensions of $40 \mathrm{~mm}$ x $40 \mathrm{~mm}$ x $12 \mathrm{~mm}$ (length $\mathrm{x}$ width $\mathrm{x}$ thickness). For each specimen, a blind hole of $8.6 \mathrm{~mm}$ depth and $20^{\circ}$ taper angle were drilled at the center of the samples. Furthermore, four DSS 2205 studs were lathed into consumable plugs of $15^{\circ}$ tapered head. The hole and the plug design are shown in Figure 3.

An appropriate friction hydro pillar process system was used for carrying out the welding experiment. The welding system is composed by a hydraulic power system to applying force $(\mathrm{kN})$, a high rotational speed welding head (rpm), an automatic control system, a data monitor and an acquisition data system. The welding system can reach $8000 \mathrm{rpm}$ and $25 \mathrm{kN}$ axially pressure force from a hydro-cylinder. In this welding process, the main settings are rotational speed, axial force, burn-off, and forging force.

To determine the welding parameters, studies cited previously were taken in consideration. The samples were divided according the welding and same forging force applied, which varied between 5 and $25 \mathrm{kN}$. For the process of the samples, the welding parameters were tested and determined according Table 2 .

For the microstructural study and microhardness test, the as-welded parts were cut into samples. The position of microstructural study was in the mixing zone of the joint weld. The cross-sections of the samples were etched with Behara modified reagent, which consist in a mixture of 20 $\mathrm{mL}$ hydrochloric acid, $80 \mathrm{~mL}$ deionized water, $1 \mathrm{~g} \mathrm{~K}_{2} \mathrm{~S}_{2} \mathrm{O}_{5}$ and $2 \mathrm{~g} \mathrm{NH}_{4} \mathrm{HF}_{2}$. The samples were etched during $15 \mathrm{~s}$ to $2 \mathrm{~min}$ by immersion. To the microstructural analysis, phase ratio $\alpha / \gamma$ and $\gamma$ spacing were used an OLYMPUS BX51M optical microscope (OM) and a SHIMADSU SSX-550 scanning electron microscope (SEM) with EDX to intermetallic analysis. Microhardness studies were carried out on the different weldments regions formed during the process using an INSTRON Tukon 2100-B Vicker's micro-hardness tester. A standard load of $500 \mathrm{gf}$ was applied for a dwell period 
Table 1: Chemical composition of base material (BM) and Plug (wt $\%)$.

\begin{tabular}{lccccccccccccccccc}
\hline Material & $\mathrm{C}$ & $\mathrm{Si}$ & $\mathrm{Mn}$ & $\mathrm{P}$ & $\mathrm{S}$ & $\mathrm{Cr}$ & $\mathrm{Mo}$ & $\mathrm{Ni}$ & $\mathrm{Co}$ & $\mathrm{Cu}$ & $\mathrm{Nb}$ & $\mathrm{Ti}$ & $\mathrm{V}$ & $\mathrm{W}$ & $\mathrm{N}$ & $\mathrm{Balance}$ \\
\hline $\mathrm{BM}$ & 0,02 & 0,52 & 1,65 & 0,02 & 0,003 & 22,9 & 3,16 & 4,74 & 0,05 & 0,19 & 0,03 & 0,004 & 0,08 & 0,09 & 0,19 & $\mathrm{Fe}$ & \\
Plug & 0,03 & 0,57 & 1,45 & 0,02 & 0,003 & 23 & 2,72 & 5,09 & 0,04 & 0,08 & 0,03 & 0,004 & 0,07 & 0,09 & 0,2 & $\mathrm{Fe}$ \\
\hline
\end{tabular}

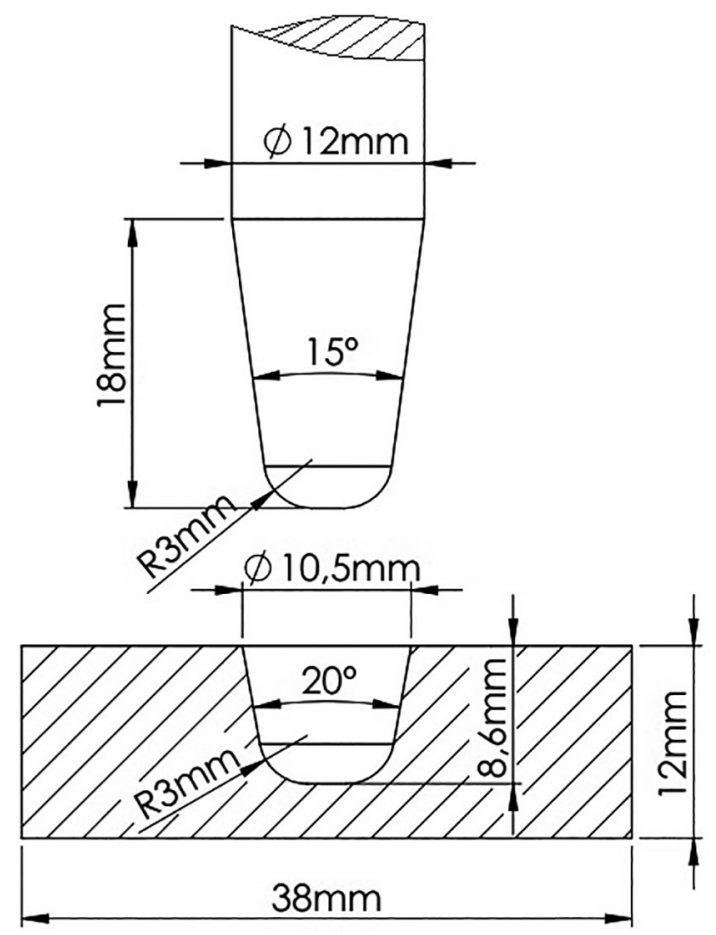

Figure 3: Dimensions of tapered consumable plugs and tapered hole.

Table 2: Welding parameters.

\begin{tabular}{lccccc}
\hline Sample & $\begin{array}{c}\text { Rotational } \\
\text { speed } \\
{[\mathrm{rpm}]}\end{array}$ & $\begin{array}{c}\text { Welding } \\
\text { force } \\
{[\mathrm{kN}]}\end{array}$ & $\begin{array}{c}\text { Forging } \\
\text { force } \\
{[\mathrm{kN}]}\end{array}$ & $\begin{array}{c}\text { Burn- } \\
\text { off } \\
{[\mathrm{mm}]}\end{array}$ & $\begin{array}{c}\text { Forging } \\
\text { time } \\
{[\mathrm{s}]}\end{array}$ \\
\hline $5 \mathrm{kN}$ & 5000 & 5 & 5 & 6 & 10 \\
$10 \mathrm{kN}$ & 5000 & 10 & 10 & 6 & 10 \\
$18 \mathrm{kN}$ & 7000 & 18 & 18 & 9 & 10 \\
$25 \mathrm{kN}$ & 7000 & 25 & 25 & 9 & 10 \\
\hline
\end{tabular}

of $10 \mathrm{~s}$ and the measurements were carried out at regular intervals of $0.25 \mathrm{~mm}$ in three different intervals of $2 \mathrm{~mm}$ from the upper surface of the welded joint.

\section{Results and Discussion}

In the FHPP process, the axial force is linked to the heat input during the welding to ensure an appropriate bond. The rotational speed is important to mixture the material of base metal with the plug in the mixing zone to ensure a joint without defects. These factors associated with the burn off determine the welding time. The acquisition data in different welding conditions were then organized and compared (Figure 4). The recorded parameters were rotational speed, time, axial force, and axial displacement.
The deformation and the heat shortage occur frequently in earlier stages of the overall FHPP process, especially in the axial force increasing phase when the stable weld process has not yet been established. As the low heat input as the short thermoplastic flow and the plug plastic deformation during welding lead to defects. The first tests showed that smaller forces lead to soldering defects known as incomplete filling and lack of bond ${ }^{9}$. Considering the characteristic of FHPP, in a proper joint geometry design, the main reason for forming weld defects might be the insufficient frictional speed ${ }^{22}$. Welded joint micrographs of the plug lower curvature radius region of 5, 10, 18 and $25 \mathrm{kN}$ cross-sections specimens are shown in Figure 5. Both the $5 \mathrm{kN}$ (Figure 5-a) and the 10 $\mathrm{kN}$ (Figure 5-b) show incomplete filling while the $18 \mathrm{kN}$ (Figure 5-c and Figure 6) shows adhesion but insufficient mixing. Lack of bond and incomplete filling are found in welds fabricated with relatively low rotational speed or low axial force. Lack of bond of the plug lower curvature radius region may appear due to inclusions and thermal contraction ${ }^{9}$.

\section{1. $25 \mathrm{kN}$ microstructures}

The micrograph in Figure 5-d show that $25 \mathrm{kN}$ welded joint with a complete bonding and therefore will be the only used in the following tests. To the $25 \mathrm{kN}$ welded joint sample, the microstructural analysis showed different zones. These zones are normally called the Heat Affect Zone of Plug (HAZ-Plug), Thermo-Mechanically Affected Zone of Plug (TMAZ-Plug), Mixing Zone (MZ), Thermo-Mechanically Affected Zone of Base Material (TMAZ-BM) and heat Affected Zone of Base Material (HAZ-BM) respectively (Figure 7).

Those DSS welded joint common microstructure zones are shown in Figure 8. In same Figure, to the next analysis, the microstructures were divided in regions called region $\mathrm{A}$, region $\mathrm{B}$, region $\mathrm{C}$ and region $\mathrm{D}$. In the Mixing Zone, all three forms of austenite phase were observed (Figure 9), i.e. grain boundary allotriomorphs (GBA), Widmanstätten (WA) structure of austenite and transgranular austenite particles $(\text { IGA })^{23}$. However WA was predominant and it occurs when higher heat input are provided ${ }^{24}$. With coarsening of WA improving the low temperature toughness, affecting corrosion state ${ }^{25}$.

The Figure 10-b-e-h show that the precipitation of secondary austenite in form of Widmanstätten needles from ferrite grain boundaries enhanced when deeper in the MZ. Yang et $\mathrm{al}^{25}$ shown that both GBA and WA had higher chromium contents and PREN (Pitting Resistance Equivalent Number) values than IGA, indicating a better pitting resistance. Gunn ${ }^{26}$ and Karlsson et al. ${ }^{27}$ already had reached these results in their DSS studies. It was observed small amount of particles of transgranular austenite (IGA), because IGA requires more driving force to nucleate inside the grains ${ }^{28}$. During cooling cycle, transformation of austenite phases was sufficient 


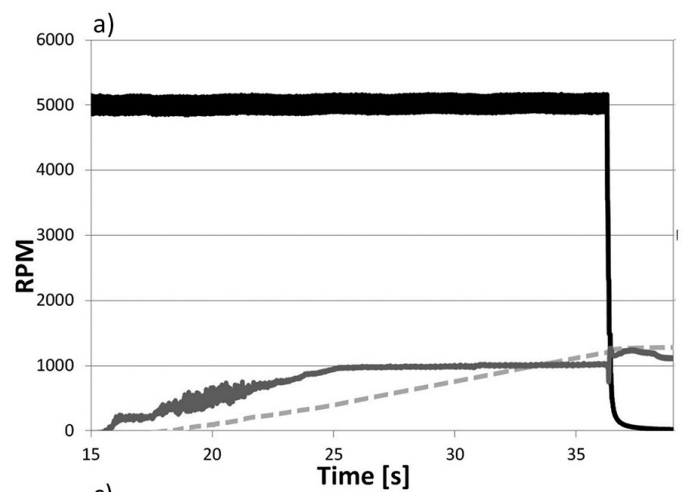

b) 30

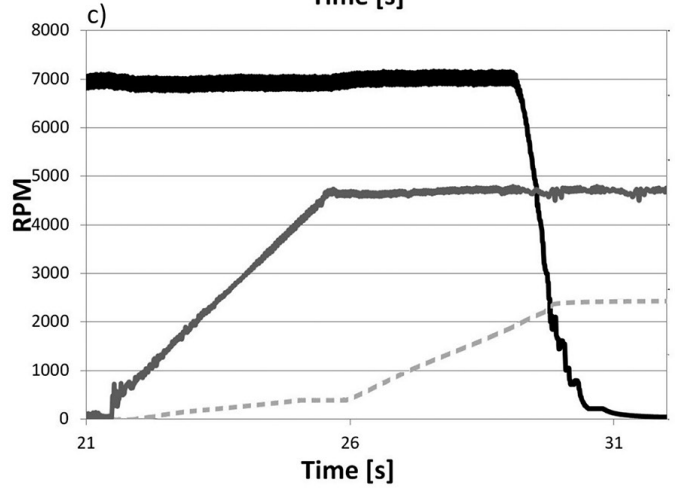

d)
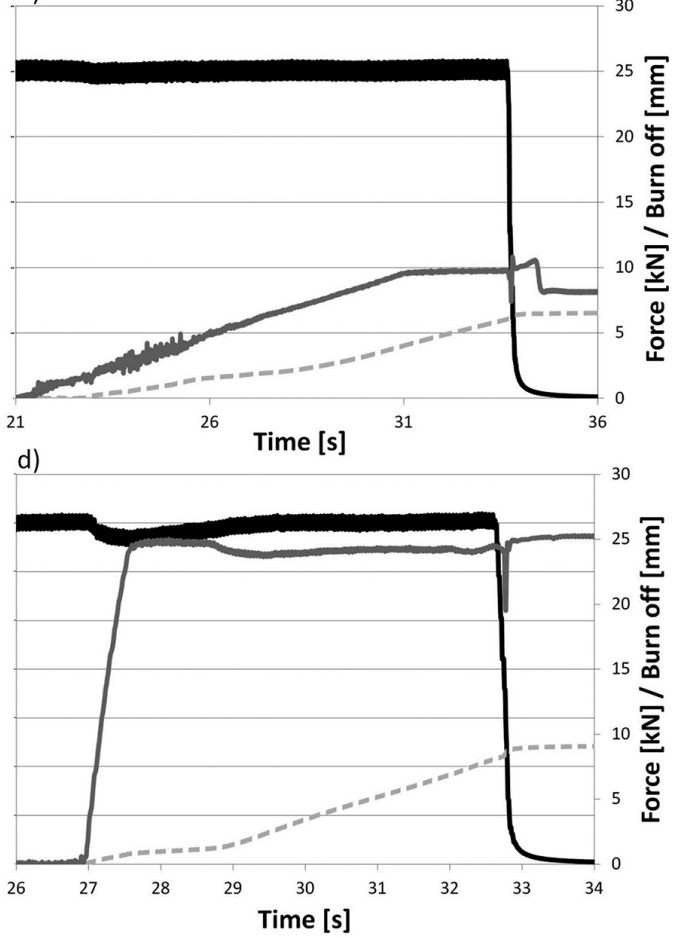

Rotational Speed [RPM]

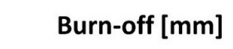

Welding Force [kN]

Figure 4: Acquisition data in different welding conditions. a) Speed 5000 RPM, Burn-off 6 mm, Force 5 kN. b) Speed 5000 RPM, Burnoff 6 mm, Force 10 kN. c) Speed 7000 RPM, Burn-off 9 mm, Force 18 kN. d) Speed 7000 RPM, Burn-off 9 mm, Force 25 kN.
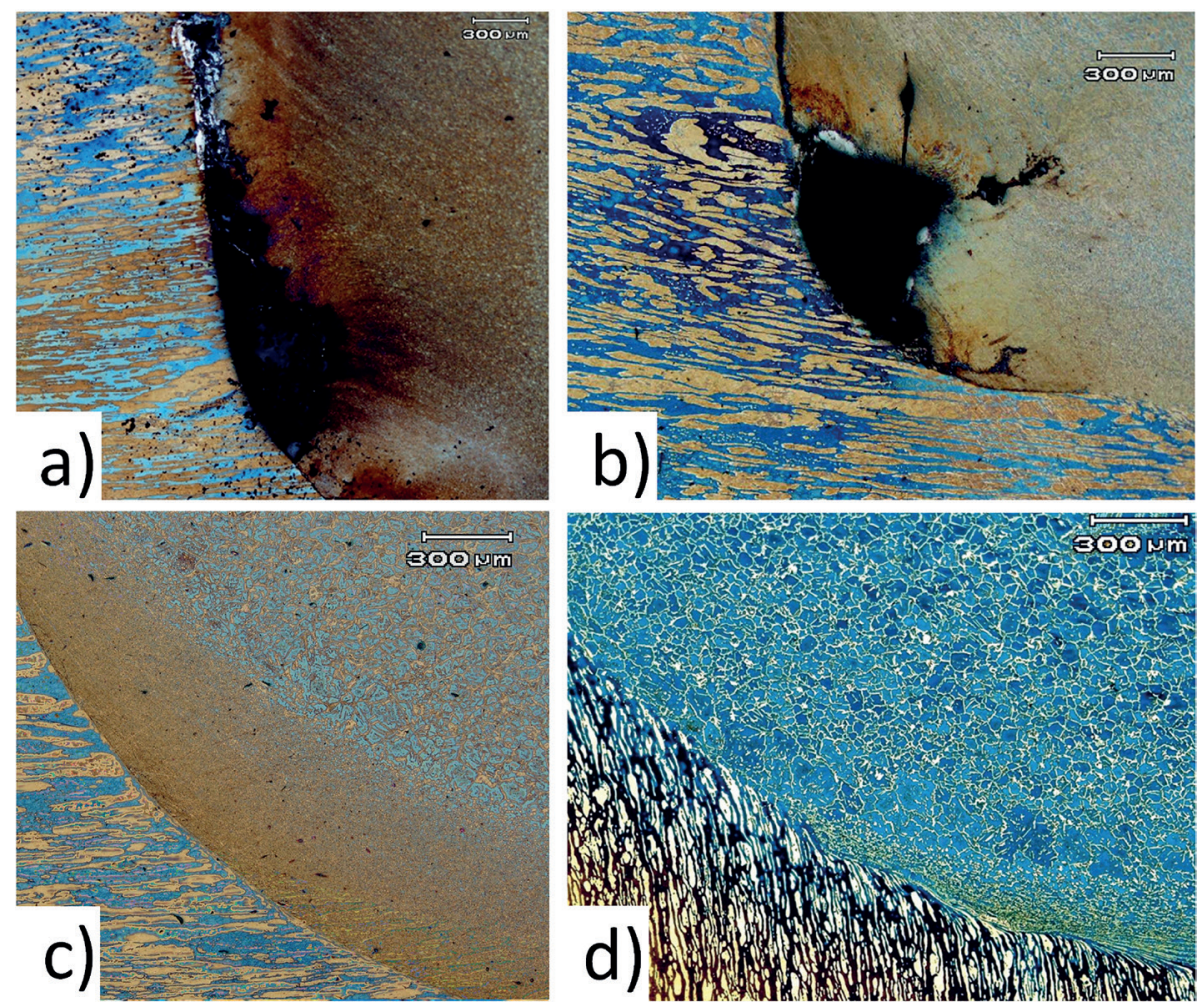

Figure 5: Micrographs. a) The force $5 \mathrm{kN}$ show incomplete. b) The force $10 \mathrm{kN}$ show incomplete filling too. c) The force $18 \mathrm{kN}$ show insufficient mixing. d) The force $25 \mathrm{kN}$ show complete bonding. 

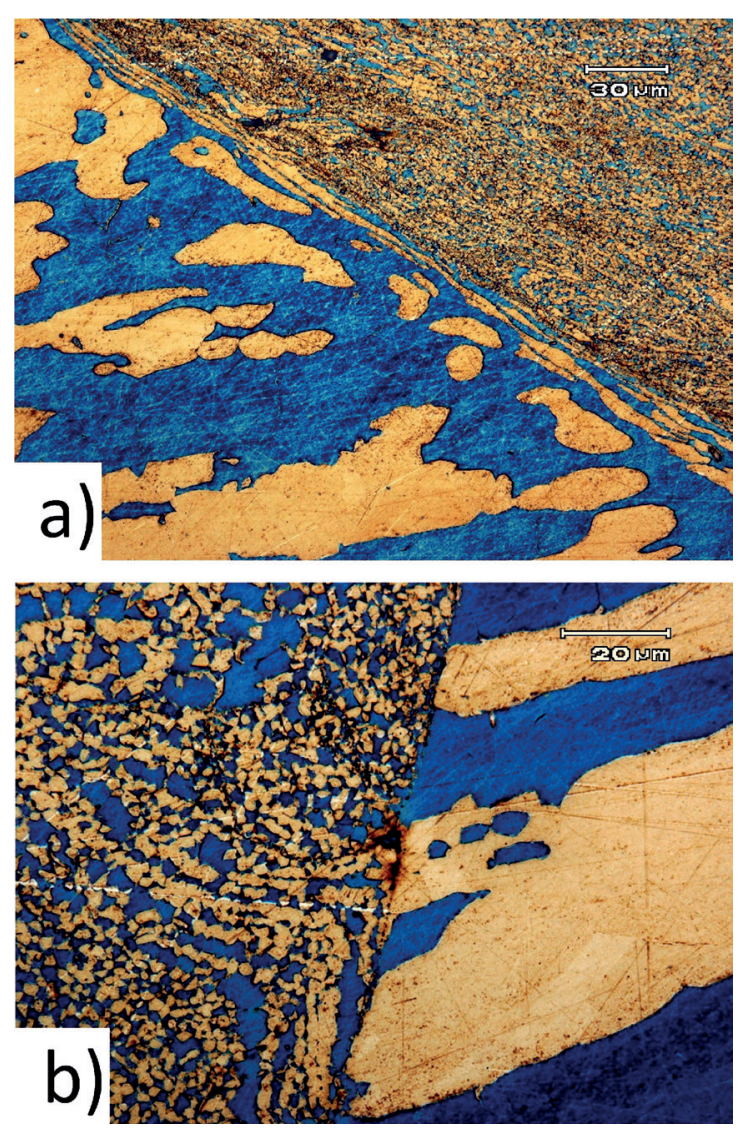

Figure 6: Micrographs of $18 \mathrm{kN}$ showing insufficient mixing and lack of bond.

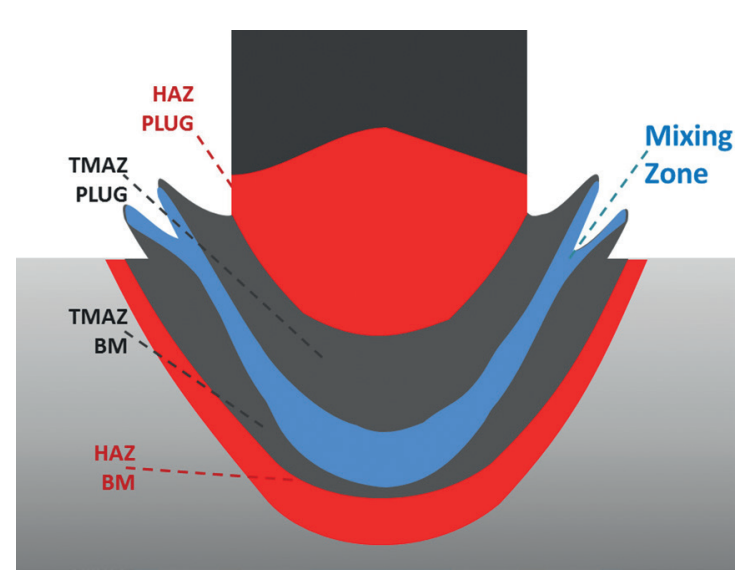

Figure 7: Schematic illustration showing the different zones observed.

in $\mathrm{MZ}$ to satisfy the duplex criteria due to rapid cooling achieved which ensures mechanical properties. MZ gave ferrite levels of 55 to $68 \%$ that are according with the recommendations from the standard DNV-RP-F ${ }^{1} 12$. (Table 3 ), being important to mention that in different heights of MZ-Regions a gradual $\alpha$-decrease was observed: A-MZ$68 \%$, B-MZ-65\%, C-MZ-61\%, D-MZ-56\%.

In the MZ, at the tip of the processed plug (Figure 10-1), is possible to see the formation of a microduplex structure. This microstructure results when a second phase

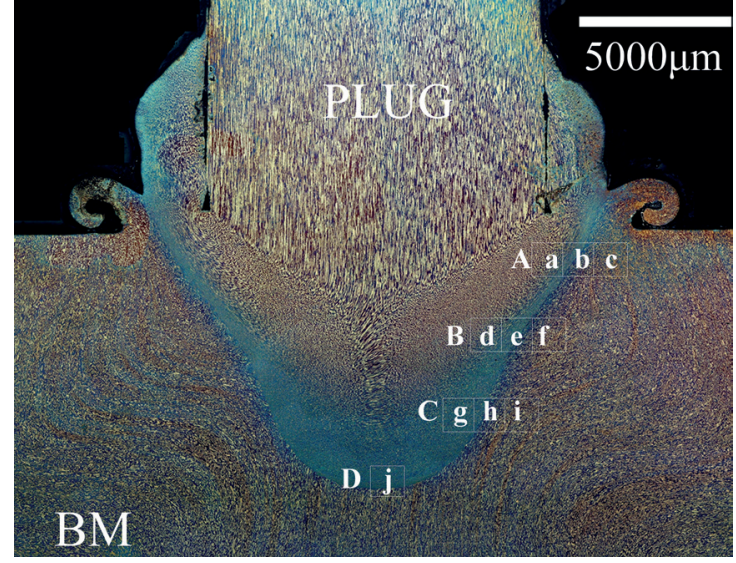

Figure 8: Microstructure $25 \mathrm{kN}$ zones divided into regions.
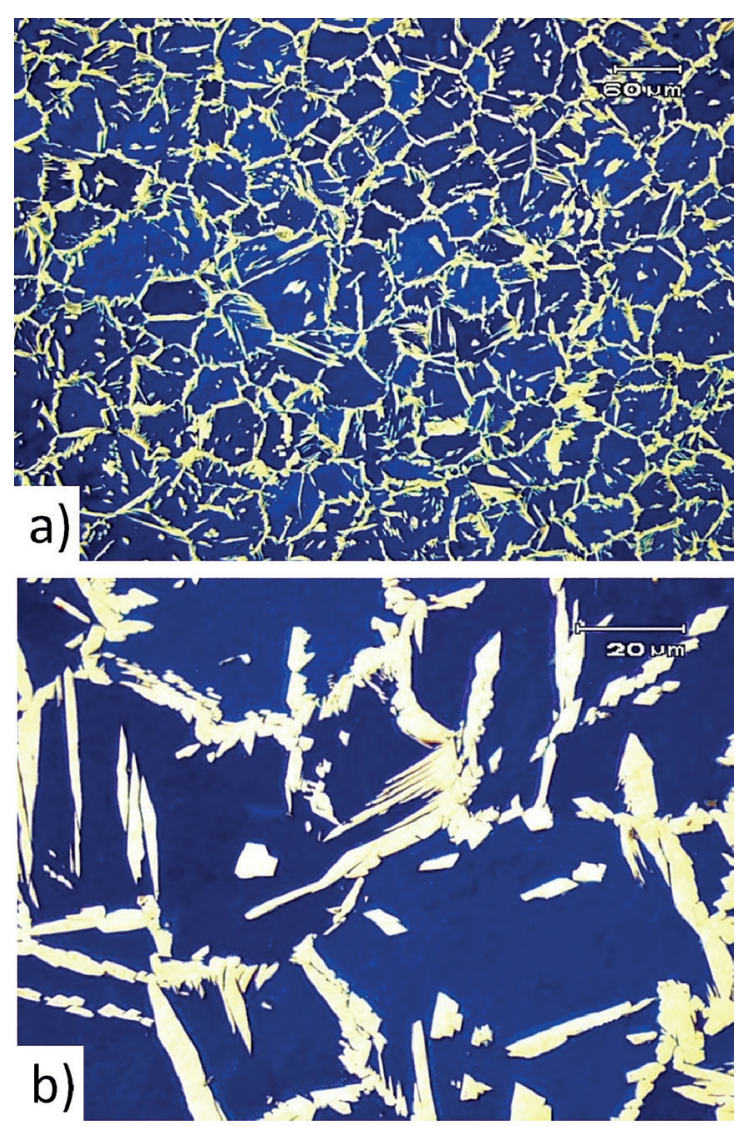

Figure 9: Mixing zone (MZ) shows Widmanstätten (WA), grain boundary allotriomorphs (GBA) and transgranular austenite particles (IGA).

precipitation precedes or occurs during recrystallization ${ }^{29}$. This microduplex structure was classified with a super-plastic behavior (elongation of several $100 \%$ before failure) ${ }^{26}$. According Gunn ${ }^{26}$, this phenomenon requires slow strain rates (a few $\mathrm{mm} / \mathrm{min}$ ), temperature of at least $0.6 \mathrm{Tm}$ (where $\mathrm{Tm}$ is the absolute melting temperature) and very fine structure. Some authors ${ }^{4,26}$ describe ways to obtains this microduplex microstructure, but it was the first time cited in FHPP welds. 

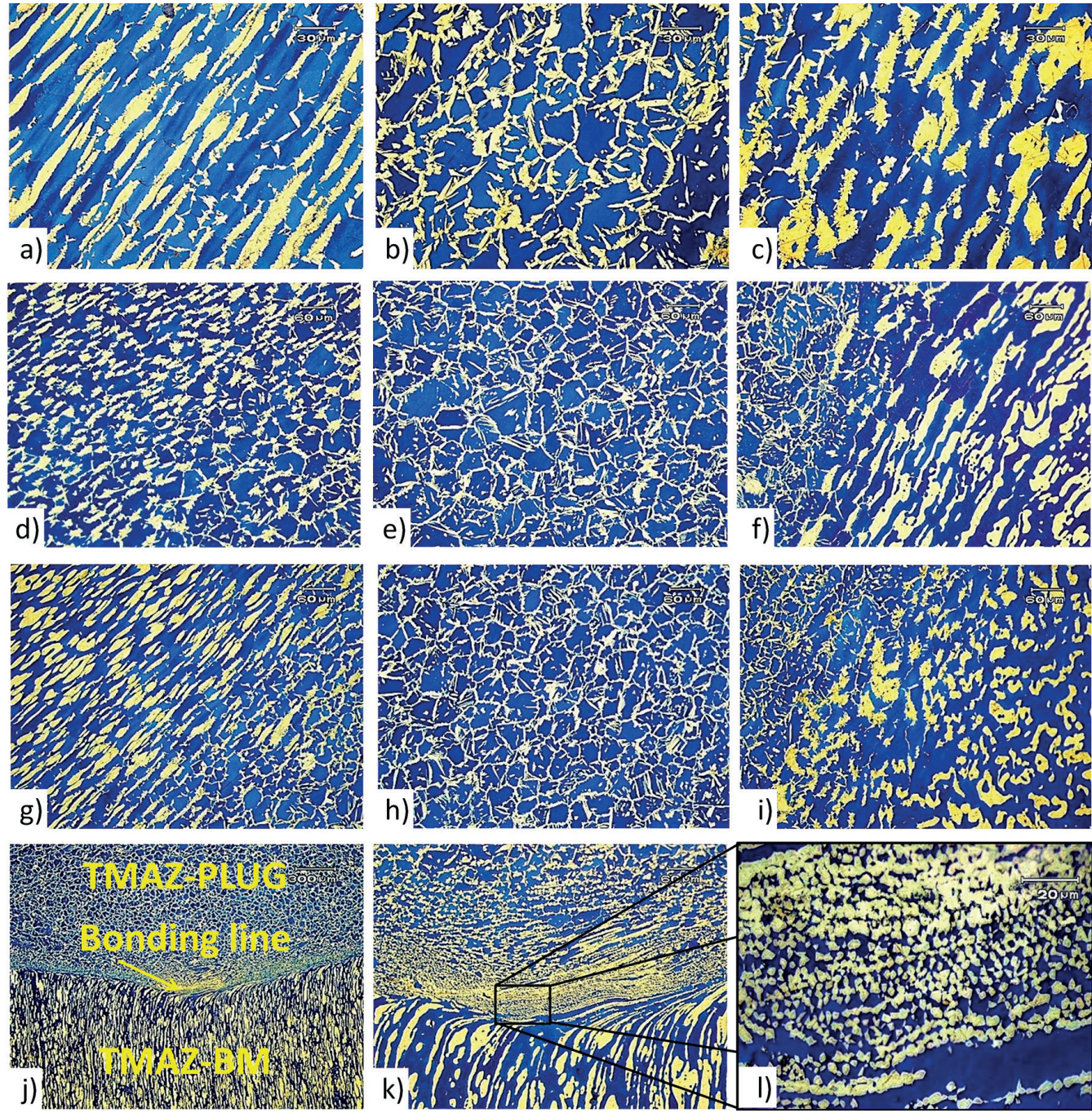

Figure 10: According to Figure 8 in different Heights, the a), d) and g) are TMAZ-Plug, the b), e) and h) are MZ, the c), f) and i) are TMAZ-BM. The j) k) and l) shows the detail of bonding tip plug.

Table 3: Ratio $\alpha / \gamma$ and $\gamma$ spacing.

\begin{tabular}{lccccccc}
\hline Region & Zone & $\alpha \%$ & $\% \mathrm{RA} \alpha$ & $\gamma \%$ & $\% \mathrm{RA} \gamma$ & $\gamma$ spacing $(\mu \mathrm{m})$ & $\% \mathrm{RA} \gamma$ spacing \\
\hline \multirow{4}{*}{ A } & TMAZ-Plug & 57,63 & 9,32 & 42,37 & 7,94 & 10,39 & 4,47 \\
& MZ & 67,69 & 12,51 & 32,31 & 4,34 & 22,78 & 6,96 \\
& TMAZ-BM & 61,17 & 5,75 & 38,83 & 5,96 & 14,76 & 3,34 \\
B & TMAZ-Plug & 67,55 & 8,71 & 32,45 & 4,74 & 11,12 & 5,36 \\
& MZ & 65,17 & 13,61 & 34,83 & 4,97 & 21,75 & 7,49 \\
& TMAZ-BM & 65,61 & 9,83 & 34,39 & 4,83 & 16,95 & 4,31 \\
C & TMAZ-Plug & 64,70 & 7,25 & 35,3 & 5,12 & 18,83 & 5,82 \\
& MZZ & 61,09 & 11,54 & 38,91 & 6,07 & 19,26 & 7,38 \\
D & TMAZ-BM & 66,43 & 9,89 & 33,57 & 4,64 & 17,70 & 6,49 \\
& TMAZ-Plug & 61,09 & 8,21 & 38,91 & 6,08 & 23,43 & 4,83 \\
Non process material & MZ & 55,83 & 14,03 & 44,17 & 8,25 & 9,03 & 9,16 \\
& PMAZ-BM & 59,98 & 7,18 & 40,02 & 7,76 & 22,43 & 8,65 \\
& Plug lengthwise & 49,63 & 4,80 & 50,37 & 4,93 & 31,54 & 6,73
\end{tabular}




\section{2. $25 \mathrm{kN}$ phase ratio $\alpha / \gamma, \gamma$ spacing and $\chi$-phase EDS analysis}

Normally, all fabrication process that tends to decrease austenite spacing are favorable because decrease the free ferrite path which generally propagates Hydrogen Induced Stress Cracking (HISC). Offshore Standard DNV-RP-F112 $2^{30}$ confirm that materials with fine phase $\gamma$ spacing have greater resistance to HISC than materials with coarse phase spacing. The austenite spacing is considered fine if it is less than 30 micrometers. In the next Table 3 is possible to see that the results as-welded of $\gamma$ spacing and phase ratio $\alpha / \gamma$ are showing containing the \%RA (relative accuracy) which proved satisfactory. Furthermore the Table 3 shows that the Austenite spacing in the MZ is approximately in the range of 4 to $24 \mu \mathrm{m}$ with a gradual decreases when going from region A to D: A-MZ-23,88 $\mu \mathrm{m}, \mathrm{B}-\mathrm{MZ}-21,77 \mu \mathrm{m}, \mathrm{C}-\mathrm{MZ}-$ $16,74 \mu \mathrm{m}, \mathrm{D}-\mathrm{MZ}-4,39 \mu \mathrm{m}$.

The weld metal and the HAZ in root area of the clad pipe seam welds, any pipe end clad welds and the seal welds of lined pipe shall be essentially free from grain boundary carbides, nitrides and intermetallic phases. Essentially free from intermetallic phases after processing implies that occasional strings of detrimental phases along the centerline of the base material is acceptable given that the phase content within one field of vision (at 400X magnification) is $<1.0 \%$ ( $\max$. $0.5 \%$ intermetallic phases $)^{31}$. In the $\mathrm{BM}$ and $\mathrm{MZ}$ region, the intermetallic phases were not found. The analysis was taken in worst detected Region which was between the HAZ-plug and TMAZ-plug. The results at 400X magnification were $<$ $0.42 \%$ intermetallic phases. In Figure 11 the microstructure of referred result. In that case, the intermetallic phase is the $\chi$-phase according other researchers ${ }^{7,32,33}$.

The intermetallic $\chi$-phase (Figure 12) can be identified on the basis of BSE (back scattered electrons) contrast in SEM because chi phase is rich in the element molybdenum ${ }^{7,34}$. Andrews $^{32}$ and another researchers ${ }^{33}$, showed that $\chi$-phase appears only in the $\mathrm{Fe}-\mathrm{Cr}-\mathrm{Mo}$ ternary and in the $\mathrm{Fe}-\mathrm{Cr}-$ $\mathrm{Ni}-\mathrm{Mo}$ and $\mathrm{Fe}-\mathrm{Cr}-\mathrm{Ni}-\mathrm{Ti}$ quaternary systems. The Energydispersive X-ray spectroscopy (EDS) showed that the large amount molybdenum in intermetallic phase Table 4.

\section{3. $25 \mathrm{kN}$ hardness analysis}

During the processing, FHPP is produced by friction and pressure. In the final process has only the action of forging pressure which the consumable plug is pressed against base material causing a severe plastic deformation. It was proposed that three main strengthening mechanisms of weld zones for friction welding: strain hardening, decreasing grain size and microstructural transformation, and probably, are those strengthening mechanisms of FHPP welds. The hardness distribution profiles of $25 \mathrm{kN}$ sample (Figure 13) which is evaluated according to the three lines testing. The results indicates that hardness values ranging from 250 HV0.5 to 290 HV0.5 are commonly found between MZ and TMAZ-Plug regions. Both in the zone HAZ-Plug as in zone HAZ-BM exhibit lower value in the range of 245-280 HV0.5, practically the same as BM. Besides, results along the four testing lines within $\mathrm{MZ}$ reveal that the hardness distribution is heterogeneous because has some singular points with higher hardness values. The increase of hardness between MZ and TMAZ-Plug indicates that materials in both regions are strengthened after welding. In previous works for $\mathrm{FHPP}^{6,35}$ shows that hardness distribution difference around the zones is common. As shown in Figure 9 and Figure 10, the microstructure of MZ is mainly secondary austenite in the form of Widmanstätten needles from the ferrite grain boundaries.

\section{Conclusions}

For the first time this DSS material was investigated in FHPP welds with forces variation from 5 to $25 \mathrm{kN}$. The results showed the efficiency in DSS structure repair using FHPP with the $25 \mathrm{kN}$ force. It was possible the production of DSS joints according with the recommendations from the standard DNV-RP-F112. The following conclusions could be drawn:

The tests showed that smaller forces lead to soldering defects known as incomplete filling and lack of bond. The FHPP with force of $25 \mathrm{kN}$ was approved according the
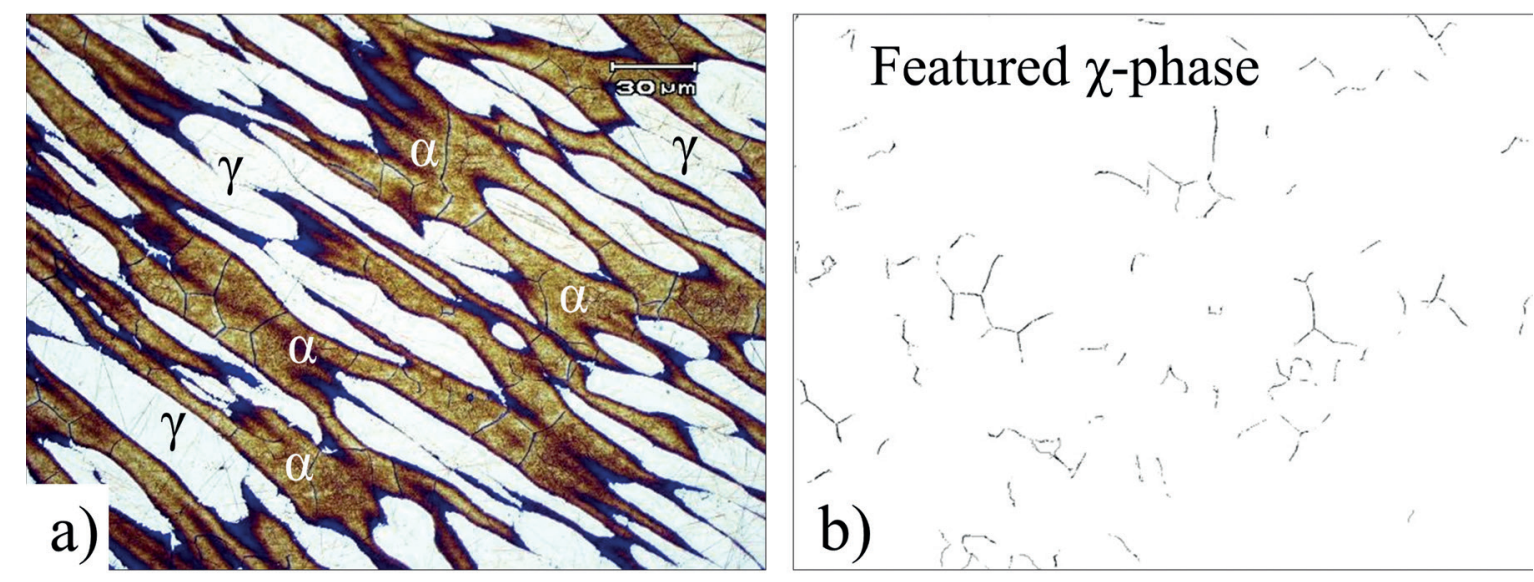

Figure 11: Microstructure of referred result used for measure $\%$ intermetallic phases according DNV-RP-F112 $2^{30}$. 

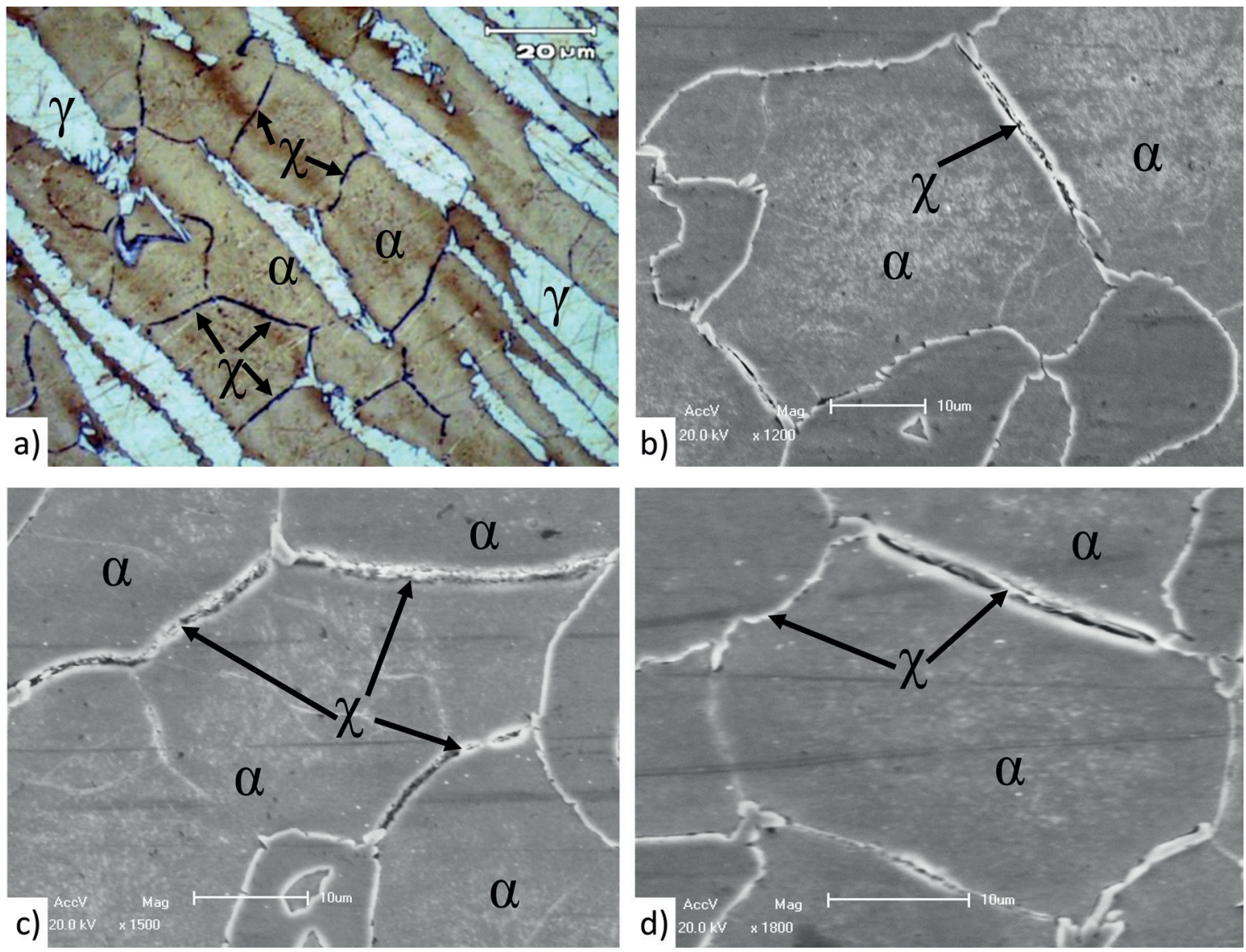

Figure 12: Scanning electron microscopy micrographs of $\alpha, \gamma$ and $\chi$ phases of the duplex stainless steel Processed by FHPP. Etching: Behara modified.

Table 4: Contents of principal metallic elements in $\gamma, \alpha$ and $\chi$-phases as determined by EDS after FHPP in DSS (wt.\%).

\begin{tabular}{ccccccc}
\hline & $\mathrm{Si}$ & $\mathrm{Cr}$ & $\mathrm{Mn}$ & $\mathrm{Mo}$ & $\mathrm{Ni}$ & $\mathrm{Fe}$ \\
\hline$\gamma$ & 0.691 & 21.22 & 2.93 & 2.51 & 6.14 & 66.51 \\
$\alpha$ & 0.919 & 23.72 & 2.64 & 3.21 & 4.21 & 65.55 \\
$\chi$ & 0.716 & 23.74 & 1.44 & 11.84 & 2.26 & 55.26 \\
\hline
\end{tabular}

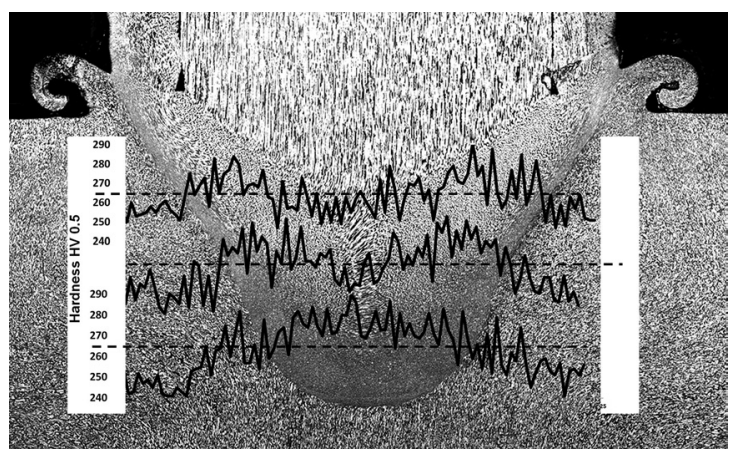

Figure 13: Hardness distribution in $25 \mathrm{kN}$ sample.

standard requirements as welded joint because was the only with a complete mixing and bonding without defects.

In Mixing zone (MZ) at the tip of the processed plug was possible to see a microduplex structure formed. It was the first time in which the microduplex structure was cited with the FHPP process and the DSS material.

In this investigation, microstructure of FHPP process in DSS reveals three distinct forms of austenite phases i.e. grain boundary allotriomorphs (GBA), Widmanstätten structure (WA) and transgranular austenite particles (IGA). The microstructure of the weldment shows excessive formation of secondary austenite phases in the form of Widmanstätten structure in the Mix zone (MZ) of the weld. The precipitation of Widmanstätten needles from the ferrite grain boundaries increases the strenght in this region.

The results as-welded $\gamma$ spacing and $\alpha$ levels was approved according the Offshore Standard DNV-RP-F112 requirements.

The intermetallic $\chi$-phase was identified. All Regions was analyzed and the one with the higher amount of $\chi$-phase presented was between the HAZ-plug and TMAZ-plug. However the results were $<0.42 \%$ intermetallic phases which is satisfactory according the standard requirements DNV AS. 
Occurred a low variation of the microhardness. The increase of hardness between MZ and TMAZ-Plug indicates that materials in both regions are strengthened after FHPP process.

\section{Acknowledgments}

The authors acknowledge the financial support of LAMEF and especially Diogo Busati, Francisco Bandeira, Facundo Lopez and Rafael Eugênio for supporting the experiment and positive suggestions.

\section{References}

1. Antony PJ, Singh Raman RK, Mohanram R, Kumar P, Raman R. Influence of thermal aging on sulfate-reducing bacteria (SRB)influenced corrosion behaviour of 2205 duplex stainless steel. Corrosion Science. 2008;50(7):1858-1864.

2. Alvarez-Armas I, Degallaix-Moreuil S. Duplex Stainless Steels. New Jersey: Wiley-ISTE; 2009. 464p.

3. Lippold JC, Kotecki DJ. Welding Metallurgy and Weldability of Stainless Steels. New Jersey: Wiley-Interscience; 2005. 376p.

4. Lo KH, Shek CH, Lai JKL. Recent developments in stainless steels. Materials Science and Engineering: R: Reports. 2009;65(4-6):39-104.

5. Michalska J, Sozańska M. Qualitative and quantitative analysis of $\sigma$ and $\chi$ phases in 2205 duplex stainless steel. Materials Characterization. 2006;56(4-5):355-362.

6. Ambroziak A, Gul B. Investigations of underwater FHPP for welding steel overlap joints. Archives of Civil and Mechanical Engineering. 2007;7(2):67-76.

7. Escriba DM, Materna-Morris E, Plaut RL, Padilha AF. Chi-phase precipitation in a duplex stainless steel. Materials Characterization. 2009;60(11):1214-1219.

8. Meyer A. Friction Hydro Pillar Processing - Bonding Mechanism and Properties. Geesthacht: GKSS; 2003. 123p.

9. Yeh FWT, Pereira da Cunha PHC, Lessa CRdeL, ClarkeT, Strohaecker, T. Evaluation of Discontinuities in A36 Steel Repairs with Friction Hydro Pillar Processing Using Different Axial Forces. ISIJ International. 2013;53(12):2269-2271.

10. Hattingh DG, Bulbring DLH, Els-Botes A, James MN. Process parameter influence on performance of friction taper stud welds in AISI 4140 steel. Materials \& Design. 2011;32(6):3421-3430.

11. Nicholas ED. Friction Processing Technologies. Welding in the World. 2003;47(11):2-9.

12. Thomas WM, Nicholas ED, Dolby RE, Jones CJ, Lilly RH, inventors. Friction plug extrusion. International patent, PCT/GB92/01540. 1992 Aug 21.

13. Yin Y, Yang X, Cui L, Cao J, Xu W. Investigation on welding parameters and bonding characteristics of underwater wet friction taper plug welding for pipeline steel. The International Journal of Advanced Manufacturing Technology. 2015;81(5):851-861. http:// dx.doi.org/10.1007/s00170-015-7281-1.

14. Baosheng Z, Xiangdong J, Jiaqing C, ZongYi Q. Numerical simulation onto the preliminary period of Friction Hydro Pillar Processing in Friction Stitch Welding. In: Proceedings of 2010 International Conference on Mechanic Automation and Control Engineering; 2010 Jun 26-28; Wuhan, China. p.5617.

15. Lessa CRde L, Caregnato MF, Cunha PHCP, Chludzinski M, Strohaecker TM, Macedo MLK, et al. Microstructural evaluation of a C-Mn steel welded by the friction hidro-pillar process. Soldagem \& Inspeção. 2011;16(1):2-11.
16. Lessa CRdeL. Soldagem FHPP - processo e metalurgia nas transformações das fases de um aço C-Mn. [Dissertation]. Porto Alegre: Universidade Federal do Rio Grande do Sul; 2011.

17 Pinheiro GA. Local Reinforcement of Magnesium Components by Friction Processing: Determination of Bonding Mechanisms and Assessment of Joint Properties. Geesthacht: GKSS-Forschungszentrum Geesthacht GmbH/Universität Hamburg; 2008.

18. Cui L, Yang X, Wang D, Hou X, Cao J, Xu W. Friction taper plug welding for S355 steel in underwater wet conditions: Welding performance, microstructures and mechanical properties. Materials Science and Engineering: A. 2014;611:15-28.

19. Gibson BT, Lammlein DH, Prater TJ, Longhurst WR, Cox CD, Ballun $\mathrm{MC}$, et al. Friction stir welding: Process, automation, and control. Journal of Manufacturing Process. 2014;16(1):56-73. http://dx.doi. org/10.1016/j.jmapro.2013.04.002

20. Blakemore G. Friction Welding - Technology for the New Millennium. In: Offshore Technology Conference; 1999 May 3-6; Houston, Texas, USA. http://dx.doi.org/10.4043/11063-MS

21. Chludzinski M. Avaliação da tenacidade à fratura em juntas soldadas por friç̧ão com pino consumivel [PhD Thesis]. Porto Alegre: Universidade Federal do Rio Grande do Sul; 2013.

22. Hattingh DG, van Zyl C. Temperature Distribution for a Friction Taper Stud Weld in Thick Walled 10CrMo910 Steel. $R \&$ D Journal of the South African Institution of Mechanical Engineering. 2012;28:37-45.

23. Badji R, Bouabdallah M, Bacroix B, Kahloun C, Belkessa B, Maza H. Phase transformation and mechanical behavior in annealed 2205 duplex stainless steel welds. Materials Characterization. 2008;59(4):447-453.

24. Ureña A, Otero E, Utrilla MV, Múnez CJ. Weldability of a 2205 duplex stainless steel using plasma arc welding. Journal of Materials Processing Technology. 2007;182(1-3):624-631.

25. Yang Y, Yan B, Li J, Wang J. The effect of large heat input on the microstructure and corrosion behaviour of simulated heat affected zone in 2205 duplex stainless steel. Corrosion Science. 2011;53(11):3756-3763.

26. Gunn R, ed. Duplex stainless steels: microstructure, properties and applications. Cambridge: Abington Publishing; 2003.

27. Karlsson L, Ryen L, Pak S. Precipitation of intermetallic phases in $22 \% \mathrm{Cr}$ duplex stainless weld metals. Weldelding Research Supplement. 1995;74:28s-40s.

28. Vinoth Jebaraj A, Ajaykumar L. Influence of Microstructural Changes on Impact Toughness of Weldment and Base Metal of Duplex Stainless Steel AISI 2205 for Low Temperature Applications. Procedia Engineering. 2013;64:456-466.

29. Davis JR, ed. Stainless Steels. Materials Park: ASM International; 1994.

30. Det Norske Veritas. Design of duplex stainless steel subsea equipment exposed to cathodic protection. Høvik: Det Norske Veritas; 2008.

31. Det Norske Veritas. Submarine Pipeline Systems. Høvik: Det Norske Veritas; 2013.

32. Andrews KW. A New Intermetallic Phase in Alloy Steels. Nature. 1949;164:1015.

33. Kasper JS. The ordering of atoms in the chi-phase of the iron-chromiummolybdenum system. Acta Metallurgica. 1954;2(3):456-461.

34. Chen TH, Weng KL, Yang J. The effect of high-temperature exposure on the microstructural stability and toughness property in a 2205 duplex stainless steel. Materials Science and Engineering: $A$. 2002;338(1-2):259-270.

35. Meyer A, Pauly D, Santos JF, Pinheiro G, Roos A, Gibson D, et al. Considerations on robotic friction stitch welding for the repair of marine structures. In: Proceedings of 20th International Conference on Offshore Mechanics and Arctic Engineering; 2001 Jun 3-8; Rio de Janeiro, RJ, Brazil. 